\title{
Novel anticoagulants in atrial fibrillation stroke prevention
}

\author{
Nicholas B Norgard, James J DiNicolantonio, Taylor J Topping and Benjamin Wee
}

\begin{abstract}
This review article evaluates novel oral anticoagulants in comparison with warfarin for thromboembolism prophylaxis in patients with atrial fibrillation (AF). AF is the most frequently diagnosed arrhythmia in the United States. The most serious side effect of AF is stroke. Warfarin has several decades of proven efficacy in AF-related stroke prevention but the drug's numerous drawbacks make its implementation difficult for practitioners and patients. The difficulties of warfarin have prompted the development of alternative anticoagulants for AF-related stroke prevention with better efficacy, safety, and convenience. The oral direct thrombin inhibitor, dabigatran, and the oral factor Xa inhibitors, rivaroxaban and apixaban, have been evaluated in a large phase III trial. Dabigatran, rivaroxaban and apixaban were shown to be noninferior compared with warfarin in the prevention of stroke. Dabigatran and apixaban were found to be statistically superior to warfarin. All three may also have a better safety profile than warfarin. In conclusion, novel anticoagulants have a different pharmacologic profile compared with warfarin that may eliminate many of the treatment inconveniences. Practitioners must also be aware of the disadvantages these new drugs possess when choosing a management strategy for their patients. Drug selection may become clearer as these new drugs are used more extensively.
\end{abstract}

Keywords: anticoagulation, apixaban, dabigatran, rivaroxaban, thromboembolism, warfarin

\section{Introduction}

Atrial fibrillation (AF) is the most frequently diagnosed arrhythmia, affecting over 2.2 million people in the United States: close to $1 \%$ of the total population. Its prevalence increases with age with as many as $10 \%$ of people older than 80 years affected. It is estimated that the number of people diagnosed with AF will approach nearly 16 million in the United States by 2050 [Miyasaka et al. 2006].

$\mathrm{AF}$ is characterized by a lack of coordinated electrical and mechanical atrial activity that promotes intra-atrial thrombus formation, primarily in the left atrial appendage. Fragments from these thrombi can then dislodge and travel to the brain to cause a stroke. The risk of stroke is increased approximately fivefold in patients with AF [Roger et al. 2011]. Up to $15 \%$ of all strokes are due to $\mathrm{AF}$ and strokes in those with $\mathrm{AF}$ are more severe and have worse outcomes than strokes in those without AF [Wolf et al. 1991; Lin et al. 1996;
Marini et al. 2005]. The mortality rate in people with AF is twice that of age-matched individuals with a normal heart rhythm driven, at least in part, by this increase risk of stroke [Lin et al. 1996]. In addition, strokes associated with AF have a significant impact on quality of life and add significantly to the economic burden of the disease [Friberg et al. 2003; Marini et al. 2005; Roger et al. 2011].

For many decades, aspirin and warfarin have been the only approved antithrombotic therapies for stroke prevention in patients with AF. Aspirin has been shown to be superior to placebo in preventing AF-related strokes [Aguilar and Hart, 2005]. However, aspirin alone or when used together with clopidogrel is less effective than warfarin and is therefore currently recommended when risk of stroke is low or when patients with $\mathrm{AF}$ cannot or will not take warfarin [Connolly et al. 2006; Mant et al. 2007; Wann et al. 2011]. Warfarin has been proven to be highly effective in preventing
Ther Adv Chronic Dis

(2012) 3(3) 123-136

DOI: $10.1177 /$

2040622312438934

(c) The Author(s), 2012. Reprints and permissions: http://www.sagepub.co.uk/ journalsPermissions.nav

Correspondence to: Nicholas B Norgard, Pharm.D.

University at Buffalo, School of Pharmacy and Pharmaceutical Sciences - Pharmacy Practice UB Center of Excellence B3-322 701 Ellicott, Buffalo, NY 14203, USA nnorgardabuffalo.edu James J DiNicolantonio, Pharm.D. Wegmans Pharmacy, Ithaca, NY, USA

Taylor J Topping, Pharm.D. University of Rochester Medical Center -

Pharmacy, Rochester, NY, USA

Benjamin Wee, Pharm.D. Kingsbrook Jewish Medical Center -

Pharmacy, Brooklyn, NY, USA 
AF-related strokes and is recommended in patients with a CHADS 2 score (a prediction score based on whether a person is 75 years or older, has heart failure, hypertension, diabetes mellitus, and/or a prior stroke or transient ischemic attack [TIA]; the higher the score, the greater the risk) of 2 or higher [Gage et al. 2001; Hart et al. 2007; Singer et al. 2008]. However, because of the difficulty in its management, a large proportion of AF patients eligible for warfarin do not receive it or receive an inadequate dose [Friberg et al. 2003; Go et al. 2003; Fang et al. 2004; Gladstone et al. 2009]. Warfarin has a narrow therapeutic window and requires frequent monitoring to reduce thrombosis risk while limiting bleeding risk. Management of warfarin is complicated by numerous food and drug interactions. Maintaining a therapeutic range has proven difficult as a significant number of patients' INRs (international normalized ratios) deviate from target range resulting in an increased risk for either thromboembolism or hemorrhage [Matchar et al. 2002; Connolly et al. 2006; Gladstone et al. 2009]. The difficulties of warfarin have prompted the development of alternative anticoagulants for AF-related stroke prevention with better efficacy, safety, and convenience. Prospective warfarin replacements include direct thrombin inhibitors and factor $\mathrm{Xa}(\mathrm{FXa})$ inhibitors. In this review we focus primarily on the novel anticoagulants that have finished a phase III trial: dabigatran, rivaroxaban, and apixaban.

\section{Warfarin}

The efficacy of warfarin in the prevention of stroke and systemic embolization in patients with atrial fibrillation has been studied in numerous trials [Petersen et al. 1989; The Boston Area Anticoagulation Trial for Atrial Fibrillation Investigators, 1990; Stroke Prevention in Atrial Fibrillation Study Investigators, 1991; Connolly et al. 1991; Ezekowitz et al. 1992; Stroke Prevention in Atrial Fibrillation II Study Investigators, 1994]. Warfarin is a vitamin $\mathrm{K}$ antagonist that causes the synthesis of biologically inactive forms of clotting factors II, VII, IX and X. As the functional forms of these clotting factors degrade the anticoagulant effect becomes apparent. The peak effect of warfarin is dependent on the clearance of factor II (plasma half-life of 60 hours or longer) and may not occur for 2-7 days following initiation of therapy [O'reilly and Aggeler, 1968]. During the initial stages of warfarin dosing, a thrombogenic effect can occur from the depletion of naturally occurring anticoagulants protein $\mathrm{C}$ and protein $\mathrm{S}$. Owing to its slow onset and early procoagulant effect, higher-risk AF patients may need a parenteral anticoagulant during the initiation or interruptions of therapy to bridge the patient until warfarin reaches peak effect [Singer et al. 2008]. The pharmacodynamic effects of warfarin are measured using the INR. An INR between 2.0 and 3.0 has been generally recommended to balance safety and efficacy for most patients with $\mathrm{AF}$ who receive warfarin anticoagulation. The lack of appropriate monitoring may lead to a significant amount of warfarin-related adverse events [Gurwitz et al. 2007]. Monitoring of INR and dose adjustments of warfarin are frequently required. Daily monitoring is needed initially and monthly monitoring is needed after a steady state has been established [Singer et al. 2008]. Strict INR control is important to improve patient outcome [The European Atrial Fibrillation Trial Study Group, 1995; Jones et al. 2005; White et al. 2007], but is difficult to achieve. A large and increasing number of drugs interact with warfarin leading to over-anticoagulation, under-anticoagulation, or increased bleeding [Holbrook et al. 2005; Juurlink, 2007]. Differences in the dietary content of vitamin $\mathrm{K}$ are known to profoundly alter the pharmacodynamic effects of warfarin [Franco et al. 2004; Khan et al. 2004; Kurnik et al. 2004; Schurgers et al. 2004; Couris et al. 2006; Rohde et al. 2007; De Assis et al. 2009]. Warfarin is extensively metabolized in the liver by the cytochrome P-450 2C9 (CYP2C9) isoenzyme. Possession of a variant allele $\left(\mathrm{CYP} 2 \mathrm{C} 9{ }^{\star} 2\right.$ and CYP2C9*3) greatly reduces warfarin metabolism and is associated with an increased risk of overanticoagulation and of bleeding events [Aithal et al. 1999; Taube et al. 2000; Leung et al. 2001; Higashi et al. 2002; Meckley et al. 2008]. Polymorphisms in the gene coding for the vitamin K epoxide reductase complex 1 (VKORC1), the target protein for warfarin, leads to a protein that is either sensitive or resistant to warfarin inhibition. It is estimated that genetic alterations in CYP2C9 and VKORC1 together with age and body size could explain as much as $63 \%$ of warfarin dose variability [Herman et al. 2006; Vecsler et al. 2006].

Warfarin is among the top 10 drugs with the largest number of serious adverse event reports submitted to the United States Food and Drug Administration (FDA) during last 20 years. The major safety concern of warfarin is the risk of major bleeding. Major bleeding from warfarin 
Table 1. Pharmacokinetics of novel anticoagulants.

\begin{tabular}{|c|c|c|c|}
\hline & $\begin{array}{l}\text { Rivaroxaban [Weinz } \\
\text { et al. 2009] }\end{array}$ & $\begin{array}{l}\text { Dabigatran [Blech } \\
\text { et al. 2008] }\end{array}$ & $\begin{array}{l}\text { Apixaban [Raghavan } \\
\text { et al. 2009] }\end{array}$ \\
\hline Dosing & 20 mg daily & 150 mg twice daily & $5 \mathrm{mg}$ twice daily \\
\hline Bioavailability & $66 \%$ (20 mg dose) & $6-7 \%$ & $50-85 \%$ \\
\hline Volume of distribution & $\sim 501$ & $60-701$ & $16-251$ \\
\hline Half-life & $\begin{array}{l}5-9 \mathrm{~h}(<45 \text { years old }) \\
11-13 \mathrm{~h}(>60 \text { years old })\end{array}$ & $\begin{array}{l}12-17 \mathrm{~h} \text {; renal } \\
\text { impairment, } \\
15-34.1 \mathrm{~h}\end{array}$ & $12-15 h$ \\
\hline $\begin{array}{l}\text { Onset of maximal } \\
\text { effect }\end{array}$ & $2-4 \mathrm{~h}$ & $1-2 \mathrm{~h}$ & $1-3 h$ \\
\hline $\begin{array}{l}\text { Offset of } \\
\text { pharmacodynamic } \\
\text { effect }\end{array}$ & $24-48 \mathrm{~h}$ & $\begin{array}{l}\text { Parallels } \\
\text { elimination half-life }\end{array}$ & $\begin{array}{l}\text { Parallels elimination } \\
\text { half-life }\end{array}$ \\
\hline Route of elimination & $\begin{array}{l}66 \% \text { renal secretion (36\% } \\
\text { unchanged drug); } \\
\text { hepatic metabolism: } 32 \% \\
\text { via CYP3A4/5 (primary) } \\
\text { and CYP2J2, } 14 \% \text { via non- } \\
\text { CYP hydrolysis }\end{array}$ & $\begin{array}{l}80 \% \text { renal } \\
\text { excretion; minimal } \\
\text { hepatic metabolism }\end{array}$ & $\begin{array}{l}25 \% \text { renal excretion; } \\
55 \% \text { via fecal route; } \\
\text { hepatic metabolism } \\
\text { via CYP3A4/3A5 }\end{array}$ \\
\hline $\begin{array}{l}\text { Potential drug } \\
\text { interactions }\end{array}$ & $\begin{array}{l}\text { Potent CYP3A4 inhibitors } \\
\text { and P-gp inhibitors* }\end{array}$ & $\begin{array}{l}\text { Potent P-gp } \\
\text { inhibitors* }\end{array}$ & $\begin{array}{l}\text { Potent CYP3A4 } \\
\text { inhibitors* }\end{array}$ \\
\hline
\end{tabular}

can lead to hospitalization, transfusion, surgery, or death. Intracranial bleeding is the most serious bleeding complication with warfarin because of the likelihood of mortality or subsequent disability.

\section{Direct thrombin inhibitors: dabigatran}

Dabigatran, in active form, is a competitive direct thrombin inhibitor that inhibits thrombindependent conversion of fibrinogen to fibrin and thrombin-induced platelet aggregation [Stangier et al. 2007, 2008; Blech et al. 2008]. It is highly selective, binding reversibly to fibrin-bound, clotbound, and free thrombin with high affinity. Dabigatran is not absorbed via the oral route. Dabigatran etexilate, which does not exhibit any anticoagulant activity, is an orally bioavailable prodrug that is rapidly converted by esterase-catalyzed hydrolysis to its active form, dabigatran. The prodrug has a poor oral bioavailability (Table 1), but nevertheless yields predictable, reproducible, and therapeutically sufficient concentrations of dabigatran. The oral bioavailability may increase by up to $75 \%$ when pellets are taken out of the hydroxypropylmethylcellulose (HPMC) capsule.
Therefore, capsules should not be opened and pellets taken alone.

The peak plasma concentrations and anticoagulant effects of dabigatran occur rapidly after oral administration $(\sim 2 \mathrm{~h})$ and reaches steady state in approximately 3 days after twice-daily dosing [Liesenfeld et al. 2006]. Dabigatran prolongs the activated partial thromboplastin time (aPTT), however drug concentration and aPTT are not linearly related, which limits the tests sensitivity. In patients who bleed or thrombose while on dabigatran, aPTT may be useful in identifying undesirable anticoagulant activity. When available, thrombin time and ecarin clotting time may be more sensitive tests to evaluate the anticoagulant effects of dabigatran. Prothrombin time and INR are prolonged by dabigatran but do not correlate well with dabigatran levels. Thus, prothrombin time and INR are not appropriate to assess dabigatran anticoagulant effects [Eriksson et al. 2008].

The anticoagulant effects of dabigatran decline in parallel with declining plasma concentrations of the drug [Stangier, 2008]. It is predominantly excreted via the renal pathway as unchanged drug 
Table 2. Study populations from phase III trials.

\begin{tabular}{|c|c|c|c|}
\hline & RE-LY & ROCKET & ARISTOTLE \\
\hline Comparator & Warfarin & Warfarin & Warfarin \\
\hline$N$ & 18,113 & 14,264 & 18,201 \\
\hline Age & 72 & 73 & 70 \\
\hline Prior stroke & $20 \%$ & $55 \%$ & $19 \%$ \\
\hline HTN & $79 \%$ & $91 \%$ & $87 \%$ \\
\hline $\mathrm{HF}$ & $32 \%$ & $63 \%$ & $35 \%$ \\
\hline Myocardial infarction & $17 \%$ & $17 \%$ & $14 \%$ \\
\hline Diabetes & $23 \%$ & $39 \%$ & $25 \%$ \\
\hline $\mathrm{CHADS}_{2}$ & 2.1 & 3.5 & 2.1 \\
\hline Previous warfarin use & $50 \%$ & $62 \%$ & $57 \%$ \\
\hline $\begin{array}{l}\text { INR values in } \\
\text { therapeutic range in } \\
\text { warfarin group }\end{array}$ & $64 \%$ & $55 \%$ & $62.2 \%$ \\
\hline \multicolumn{4}{|c|}{$\begin{array}{l}\text { ARISTOTLE, Apixaban for Reduction In STroke and Other ThromboemboLic Events in atrial fibrillation; } \text { CHADS }_{2} \text {, a } \\
\text { prediction score based on whether a person is } 75 \text { years or older, has heart failure, hypertension, diabetes mellitus, } \\
\text { and/or a prior stroke or transient ischemic attack; the higher the score, the greater the risk; HF, heart failure; HTN, } \\
\text { hypertension; INR, international normalized ratio; RE-LY, Randomized Evaluation of Long term anticoagulant therapy; } \\
\text { ROCKET, Rivaroxaban-once daily, oral, direct factor Xa inhibition compared with vitamin K antagonism for prevention of } \\
\text { stroke and Embolism Trial in Atrial Fibrillation. }\end{array}$} \\
\hline
\end{tabular}

through glomerular filtration. The half-life of dabigatran is significantly prolonged and the exposure to the drug is increased in patients with renal impairment (1.5-, 3.2-, and 6.3-fold increase in subjects with mild, moderate, and severe renal impairment) [Stangier et al. 2010]. This increases the risk of bleeding as there is a clear association of higher dabigatran plasma concentrations and the occurrence of bleeding events [Connolly et al. 2009].

Dabigatran has minimal potential drug-drug interactions since cytochrome $\mathrm{P} 450$ isoenzymes are not involved in its metabolism, and it neither induces nor inhibits cytochrome $\mathrm{P} 450$ isoenzyme activity [Stangier et al. 2007, 2008; Blech et al. 2008; Stangier, 2008]. Dabigatran etexilate, the prodrug, is a substrate of the efflux transporter P-glycoprotein (P-gp). Potent P-gp inhibitors, ketoconazole, verapamil, and amiodarone, increase prodrug absorption and lead to modest increases in dabigatran plasma concentrations [Walenga and Adiguzel, 2010].

The clinical efficacy of dabigatran was studied in the RE-LY (Randomized Evaluation of Long term anticoagulant therapy) trial [Connolly et al. 2009]. This study was a randomized, noninferiority trial of two blinded doses of dabigatran compared with open-label warfarin in subjects with nonvalvular atrial fibrillation and at least one risk factor for stroke (previous stroke or TIA or systemic embolism, left ventricular ejection fraction $<40 \%$ or symptomatic heart failure, hypertension, age $>75$ years, or age $65-74$ years with either diabetes mellitus or coronary artery disease). The study included 18,113 patients who were randomly assigned to receive dabigatran at one of two doses (110 or $150 \mathrm{mg}$ ) twice daily, or warfarin, adjusted to an INR of 2.0-3.0. Study patient characteristics are included in Table 2 . The primary efficacy outcome of stroke (including hemorrhagic stroke) or systemic embolism occurred in $1.7 \%$ patients in the warfarin group, $1.5 \% / y e a r$ in the low-dose dabigatran group, and $1.1 \%$ in the dabigatran $150 \mathrm{mg}$ group. Dabigatran $110 \mathrm{mg}$ met the criteria for noninferiority compared with warfarin (relative risk [RR] 0.91, 95\% confidence interval [CI] 0.74-1.11), while dabigatran $150 \mathrm{mg}$ was significantly more effective than warfarin (RR 0.66 , $95 \% \mathrm{CI} 0.53-0.82)$ or dabigatran $110 \mathrm{mg}$ (RR $0.73,95 \%$ CI $0.58-0.91)$. The superiority of dabigatran $150 \mathrm{mg}$ was principally driven by reductions in strokes (RR $0.64,95 \%$ CI $0.51-$ $0.81)$. The rates of hemorrhagic stroke were significantly lower in the dabigatran 110 and 150 mg groups $(0.1 \% /$ year for both doses) compared with warfarin $(0.4 \%$ /year; $p<0.001$ for both doses). Subgroup analyses of the RE-LY trial were consistent with the overall results, confirming its findings in patients with a prior stroke, in 
patients with different $\mathrm{CHADS}_{2}$ scores, as well as in patients undergoing cardioversion [Diener et al. 2010; Oldgren et al. 2010; Nagarakanti et al. 2011].

The benefit of warfarin relates directly to the time patients spend at therapeutic INR range of between 2.0 and 3.0 [Connolly et al. 2008]. In RE-LY, the mean percentage of the time the warfarin group had a therapeutic INR was $64 \%$, which reflects the real-life problem with this medication. The benefits of dabigatran are greater when INR is poorly controlled [Wallentin et al. 2010].

The risk of major bleeding was significantly less with dabigatran $110 \mathrm{mg}$ than warfarin (RR 0.80, 95\% CI 0.69-0.93), and dabigatran $150 \mathrm{mg}$ was not significantly different compared with warfarin $(0.93,95 \%$ CI 0.81-1.07). High-dose dabigatran was associated with significantly more major gastrointestinal bleeding than was warfarin (RR 1.50, 95\% CI 1.19-1.89). Intracranial bleeding occurred less frequently with dabigatran compared with warfarin $(p<0.001$ for both doses). The major adverse effect of dabigatran was dyspepsia, which occurred in $5.8 \%$ of the warfarin group and significantly more frequently in the dabigatran groups $(11.8 \%$ for 110 $\mathrm{mg} ; 11.3 \%$ for $150 \mathrm{mg} ; p<0.001$ for both doses) and may have contributed to the high dropout rate in patients taking dabigatran (21\%) as compared with warfarin (17\%) [Gage, 2009].

The rates of myocardial infarction showed a trend to be higher with dabigatran than with warfarin. They were $0.53 \%$ /year with warfarin, $0.72 \% /$ year with low-dose dabigatran $(p=0.07)$, and $0.74 \%$ / year with high-dose dabigatran $(p=0.048)$. The reason for the increase in myocardial infarction is yet to be resolved. One theory is that rather than promoting myocardial infarction, dabigatran provides less protection from myocardial infarction than warfarin. However, there is no statistical evidence for that. Dabigatran has been shown to increase urinary 11-dehydrothromboxane $\mathrm{B}_{2}$ in patients who do not receive aspirin, suggesting a potential platelet-activating effect of dabigatran in the absence of concomitant aspirin treatment [Ezekowitz et al. 2007]. The clinical relevance of the small increase in myocardial infarction remains in question since cardiovascular mortality was reduced in the dabigatran group. In addition, after a reanalysis of study data the increase in myocardial infarction went from significant to nonsignificant: RR 1.27 (95\% CI 0.94-1.71; $p=0.12$ ) [Connolly et al. 2010].

Dabigatran was shown, in a small study, to be safe for use as postprocedural anticoagulation to prevent thromboembolic events following AF ablation [Winkle et al. 2011]. One hundred and twenty-three consecutive patients were given enoxaparin $0.5 \mathrm{mg} / \mathrm{kg}$ immediately following the procedure and was repeated 12 hours later. Patients were started on dabigatran 22 hours postablation evaluated for thromboembolic events, bleeding complications, and side effects over a 30-day follow-up period. There were no postablation strokes, TIAs, or systemic thromboembolic events in any patient. Two patients discontinued dabigatran because of gastrointestinal side effects and one because of a diffuse rash.

Dabigatran, at a dose of $150 \mathrm{mg}$ twice daily, was approved for the prevention of embolic events in patients with $\mathrm{AF}$ with a creatinine clearance $(\mathrm{CrCl})>30 \mathrm{ml} / \mathrm{min}$ by the US FDA. The $110 \mathrm{mg}$ twice-daily dose used in the RE-LY trial did not receive FDA approval. In patients with a $\mathrm{CrCl}$ of $15-30 \mathrm{ml} / \mathrm{min}$, the approved dose is $75 \mathrm{mg}$ twice daily. This dose is currently marketed in Europe but was not evaluated in the RE-LY trial. There are no dosing recommendations for patients with $\mathrm{CrCl}<15 \mathrm{ml} / \mathrm{min}$ or patients on dialysis.

\section{Factor Xa inhibitors}

\section{Rivaroxaban}

Rivaroxaban is an orally administered, direct $\mathrm{FXa}$ inhibitor that differs from parenteral $\mathrm{FXa}$ inhibitors, such as fondaparinux, because it does not require antithrombin III to elicit its anticoagulant effects. FXa plays a central role in coagulation by mediating thrombin formation. One molecule of FXa is able to generate more than 1000 molecules of thrombin. Thrombin has several functions in blood coagulation, including the conversion of fibrinogen to fibrin, the activation of platelets, and the feedback activation of other coagulation factors, resulting in the amplification of its own formation. Rivaroxaban produces antithrombotic effects by decreasing the generation of thrombin, through FXa inhibition, thus diminishing thrombin-mediated activation of both coagulation and platelets, without affecting the activity of thrombin itself. 
Rivaroxaban has a high oral bioavailability and rapidly achieves peak plasma concentrations and anticoagulant effects (Table 1). Rivaroxaban demonstrates predictable and reproducible pharmacokinetics negating the need for routine therapeutic monitoring [Kubitza et al. 2005].

Rivaroxaban does prolong the prothrombin time (PT) and aPTT in a dose-dependent way with little observed interindividual variability based on age, gender, or body weight [Kubitza et al. 2005, 2007, 2008]. These coagulation tests can be used to monitor rivaroxaban if anticoagulant effect is in question. PT appears to be best for following the effect of rivaroxaban in clinical settings. The INR should not be used for rivaroxaban because it is only calibrated and validated for coumarins.

Rivaroxaban has a limited potential to be subject to drug-drug interactions compared with warfarin because of its dual mode of elimination. Rivaroxaban is primarily eliminated by renal excretion and approximately one-third of the drug is metabolized by the liver (CYP3A4/3A5 > CYP2J2 > non-CYP mediated hydrolysis) [Weinz et al. 2009]. Subjects with renal or hepatic impairment experience a decrease in the clearance of the drug, which increases rivaroxaban exposure and the risk for bleeding [Halabi et al. 2007; Kubitza et al. 2010]. Concomitant administration with drugs that are strong inhibitors or inducers of both hepatic metabolism are likely to result in a clinically relevant increase in systemic drug exposure to rivaroxaban. For instance, rivaroxaban exposure and response are significantly increased when administered concomitantly with ketoconazole and ritonavir (2.6- and 2.5-fold increase, respectively) [Eriksson et al. 2009]. Individuals with mild ( $\mathrm{CrCl} 50-79 \mathrm{ml} / \mathrm{min}$ ), moderate ( $\mathrm{CrCl} 30-49 \mathrm{ml} / \mathrm{min})$, and severe $(\mathrm{CrCl}<30 \mathrm{ml} /$ $\mathrm{min}$ ) renal impairment, have a significant increase in the inhibition of $\mathrm{FXa}$ (1.5-, 1.9-, 2.0-fold, respectively) and PT prolongation (1.3-, 2.2-, 2.4-fold, respectively) compared with individuals with normal renal function [Kubitza et al. 2010].

The efficacy of rivaroxaban was studied in the ROCKET-AF (Rivaroxaban-once daily, oral, direct factor Xa inhibition compared with vitamin $\mathrm{K}$ antagonism for prevention of stroke and Embolism Trial in Atrial Fibrillation), a randomized, double-blind, double-dummy study of 14,264 patients with nonvalvular atrial fibrillation [Patel et al. 2011]. Patients were randomly assigned to receive either rivaroxaban $20 \mathrm{mg}$ daily or warfarin adjusted to an INR of 2-3. The characteristics of study patients are included in Table 2. This noninferiority trial demonstrated that rivaroxaban was at least as effective as warfarin. In the strict intention-to-treat analysis, the primary outcome of stroke or non-CNS systemic embolism occurred in $1.7 \%$ in the rivaroxaban group and $2.2 \%$ in the warfarin group ( $p$ for noninferiority $<0.001)$. However, rivaroxaban was not statistically superior to warfarin in the intention-to-treat analysis $(p=0.117)$. In the prespecified analysis of the patients who remained on treatment over the course of the trial, rivaroxaban was superior to warfarin (1.70 versus 2.15; hazard ratio [HR] $0.79 ; 95 \%$ CI 0.65-0.95, $p=0.015)$. There was no significant difference in ischemic stroke, however hemorrhagic stroke was significantly reduced in the rivaroxaban group (HR $0.59,95 \%$ CI $0.37-0.93, p=0.024)$.

There were fewer intracranial bleeds with rivaroxaban $(0.5$ versus 0.7 ; HR 0.67 ; 95\% CI 0.47 $0.94 ; p=0.019)$ and fewer deaths from bleeding ( 0.24 versus 0.48 ; HR 0.50 ; $95 \%$ CI $0.31-0.79$; $p=0.003)$. However, the rivaroxaban group had more bleeds requiring transfusions (1.65 versus $1.32 ; p=0.044)$ and drops in hemoglobin $(2.77$ versus $2.26 ; p=0.019)$. Any serious adverse event occurred in approximately $40 \%$ of patients in both treatment groups and either study drug was prematurely discontinued in about $15 \%$ of patients.

In September 2011, the US FDA Cardiovascular and Renal Drugs Advisory Committee recommended the approval of rivaroxaban for the prevention of stroke in patients with atrial fibrillation.

\section{Apixaban}

Apixaban is an oral, selective, direct acting/reversible FXa inhibitor. Like rivaroxaban, it does not require antithrombin for antithrombotic activity and inhibits free as well as prothrombinaseand clot-bound FXa activity. Apixaban is rapidly absorbed with good bioavailability (Table 1). It reaches peak concentrations approximately 1-3 hours after administration reaching steady-state concentrations after 3 days. This translates into a rapid onset of action as apixaban evokes increases in aPTT and PT that parallel its plasma concentrations. Approximately $25 \%$ of the apixaban is excreted unchanged in the urine and about $25 \%$ is excreted unchanged in the feces. The remaining 
drug is oxidized to several inactive metabolites compounds, partly by CYP3A4/3A5 enzymes in the liver. The multiple elimination pathways suggest that apixaban can be used in patients with hepatic or renal impairment and that the likelihood of significant drug-drug interactions is low [Wang et al. 2010].

The AVERROES (Apixaban Versus Acetylsalicylic Acid [ASA] to Prevent Stroke in Atrial Fibrillation Patients Who Have Failed or Are Unsuitable for Vitamin K Antagonist Treatment) study was designed to compare the efficacy and safety of apixaban versus aspirin in patients with atrial fibrillation and who, for a variety of reasons, were not candidates for warfarin [Connolly et al. 2011]. This double-blind, double-dummy superiority trial enrolled 5599 patients who were randomized to receive either apixaban $5 \mathrm{mg}$ twice daily or aspirin, at a dose of 81-324 mg daily. The study population in the AVERROES trial was similar to the patient population in the RE-LY trial. The study was stopped early after a predefined interim analysis showed clear evidence of a reduction in stroke and systemic embolism. Apixaban treatment was associated with a $55 \%$ reduction in stroke (ischemic or hemorrhagic) or systemic embolism compared with aspirin over a mean follow up of 1.1 years ( $1.6 \%$ versus $3.7 \%$; HR 0.45 ; 95\% CI $0.32-0.62$; $p<0.001)$. The benefit of apixaban was most apparent in patients with $\mathrm{CHADS}_{2}$ scores of 3 or greater.

The benefit of apixaban also occurred without an increase in the risk of major bleeding compared with aspirin (1.4\% versus $1.2 \%$; HR $1.13 ; 95 \%$ CI $0.74-1.75 ; p=0.57)$. This includes no increased risk of fatal bleeds $(0.1 \%$ versus $0.2 \% ; p=0.53)$ or intracranial hemorrhage $(0.4 \%$ versus $0.4 \%$; $p=0.69$ ). Serious adverse events of any kind occurred more frequently in the aspirin group and events leading to permanent discontinuation of the study medication were significantly lower in the apixaban group (17.9\%/year versus $20.5 \%$ / year; $p=0.03$ ).

Apixaban was compared head-to-head with warfarin at reducing the risk of stroke (ischemic or hemorrhagic) and systemic embolism in $\mathrm{AF}$ patients in the ARISTOTLE (Apixaban for Reduction In STroke and OtherThromboemboLic Events in atrial fibrillation) trial [Granger et al. 2011]. The trial randomized $18,201 \mathrm{AF}$ patients to apixaban (5 mg orally twice daily) or warfarin (target INR of 2.0-3.0). The study population in the ARISTOTLE trial was similar to the study populations in the AVERROES and RE-LY trials. After a median follow up of 1.8 years, apixaban was associated with a $21 \%$ reduction in the risk of stroke or systemic embolism (1.27\% versus $1.6 \%$; $95 \%$ CI $0.66-0.95 ; p=0.01)$, a $31 \%$ reduction in major bleeding $(2.1 \%$ versus $3.1 \%$; $95 \%$ CI 0.60 $0.80 ; p<0.001)$, and an $11 \%$ reduction in allcause mortality $(3.52 \%$ versus $3.94 \%$; $95 \%$ CI $0.80-0.99 ; p=0.047)$. As with dabigatran and rivaroxaban, apixaban resulted in lower rates of hemorrhagic stroke (HR $0.51 ; 95 \%$ CI $0.35-$ $0.75 ; p<0.001)$ and intracranial hemorrhage (HR 0.42; 95\% CI 0.30-0.58; $p<0.001$ ). Conversely to dabigatran and rivaroxaban, there was no increase in gastrointestinal bleeding with apixaban compared with warfarin.

\section{Edoxaban}

Edoxaban is a direct $\mathrm{FXa}$ inhibitor with a rapid onset of action, short half-life, 8-10 hours, and multiple elimination pathways [Ogata et al. 2010]. The majority of drug is eliminated via renal excretion and exposure to edoxaban increases in patients with renal dysfunction [Ogata et al. 2010]. Edoxaban was studied in a phase II trial that randomized 1146 subjects with $\mathrm{AF}$ (follow up of 3 months) to one of four doses of edoxaban or open-label warfarin titrated to INR 2.0-3.0 [Weitz et al. 2010]. Based on this trial, the $30 \mathrm{mg}$ once-daily and $60 \mathrm{mg}$ once-daily doses of edoxaban were selected for comparison with warfarin in a phase III double-blind, double-dummy study of patients with atrial fibrillation. The ENGAGE AF-TIMI (Effective aNticoaGulation with factor Xa next GEneration in Atrial Fibrillation) is a noninferiority trial recruiting approximately 16,500 patients with $\mathrm{AF}$ and moderate to high risk (CHADS $\geq 2$ ) of stroke [Ruff et al. 2010]. The estimated completion date is 2012 .

\section{Betrixaban}

Betrixaban is an oral direct FXa inhibitor with a long half-life $(19 \mathrm{~h})$ that allows for once-daily dosing [Zhang et al. 2009]. Betrixaban is primarily eliminated unchanged in the bile with minimal renal excretion $(<5 \%)$, which may make it particularly suitable for patients with renal failure. It is also minimally metabolized through the CYP P450 enzyme system, which may result in a low potential for drug-drug interactions [Zhang et al. 2009]. The safety and tolerability of betrixaban for stroke prevention was evaluated in 508 
patients with $\mathrm{AF}$ in a phase II dose-ranging study [Ezekowitz, 2010]. Patients with nonvalvular atrial fibrillation $(n=127)$ were randomized to one of three doses of betrixaban $(40 \mathrm{mg}, 60 \mathrm{mg}$, $80 \mathrm{mg}$ ) versus warfarin, with a goal INR of 2-3. The three tested doses of betrixaban appeared to be well tolerated. Bleeding was lowest in the betrixaban $40 \mathrm{mg}$ group, compared with higherdose betrixaban or warfarin.

\section{New anticoagulants versus warfarin}

Warfarin has several decades of proven efficacy in AF-related stroke prevention but the drug's numerous drawbacks make its implementation difficult for practitioners and patients (Table 3). Owing to this, warfarin is underused, suboptimally applied, and often discontinued in patients at high risk of stroke. An anticoagulant with equal efficacy, but with a better safety profile and/or ease of use is a big step in the management of AF patients. Rivaroxaban was shown to have an efficacy similar to warfarin, dabigatran (150 $\mathrm{mg}$ dose) was statistically superior to warfarin in the prevention of stroke or systemic embolic events and apixaban reduced stroke or systemic embolism and overall mortality compared with warfarin. These drugs may have a better safety profile than warfarin. All three new anticoagulants have shown a large reduction in intracranial hemorrhage compared with warfarin. This may be related to warfarin's inhibition of multiple coagulation factors or an interaction with tissue factor VIIa complexes in the brain [Mackman, 2009; Granger et al. 2011]. Apixaban had a substantially lower risk of bleeding and with lower rates of discontinuation. Dabigatran, on the other hand, was more likely to cause gastrointestinal bleeding and nonhemorrhagic side effects (e.g. dyspepsia) leading to drug discontinuation. None of the new anticoagulants have data in AF-patients with significant valvular disease requiring valve replacement. Warfarin remains the drug of choice in this population until data become available on the new agents.

The safety and efficacy of warfarin are dependent on the time patients spend in the therapeutic INR range [Veeger et al. 2006]. The incidence of adverse events increases substantially as the INR goes above or below therapeutic range [White et al. 2007]. Maintaining a therapeutic INR can be difficult, however new mechanisms are emerging that may improve the safety and efficacy of warfarin and reduce the inconvenience of warfarin management [Harper and Pollock, 2008; Ryan et al. 2008, 2009]. This is not an issue with the new anticoagulants since they do not have warfarin's narrow therapeutic window. They are given as a fixed dose and do not require persistent monitoring making them much more convenient. A major advantage of new anticoagulants is that they are less susceptible to the dietary and drug interactions that confound warfarin management. However, even though the need for INR monitoring is considered a detriment of warfarin therapy, it does provide an objective way to assess and respond to nonadherence and a monitoring tool in case of bleeding or thrombosis. The inability to accurately monitor the new anticoagulants may be troublesome in patients with chronic kidney disease whose dosing needs will vary according to renal function. However, PT may be used to measure the effect of rivaroxaban and anti-FXa may be used to measure apixaban in clinical settings.

A major disadvantage of the new anticoagulants is the absence of an antidote in case of serious bleeding or when an emergency intervention needs immediate correction of coagulation. Patients who require a rapid reversal of warfarin can be administered vitamin K. Prothrombin complex concentrate (PCC) has been shown to reverse the anticoagulant effect of rivaroxaban in healthy subjects [Eerenberg et al. 2011]. The effects of dabigatran were not reversed with PCC and apixaban has yet to be studied. A large clinical study on anticoagulated patients with bleeding events is necessary before implementing PCC into clinical practice. Dabigatran blood levels drop fairly rapidly after stopping the medication, so an antidote may not be essential. In the event of an acute overdose ( $<1-2$ hours), the administration of activated charcoal may be helpful in adsorbing dabigatran [Van Ryn et al. 2010]. If bleeding is catastrophic it is possible to dialyze the patient, because dabigatran is dialyzable.

To the advantage of the new anticoagulants, the rapid onset/offset of these drugs allows them to be stopped before a procedure and restarted without bridging, whereas warfarin requires $3-5$ days interruption before a procedure, often with bridging therapy to deal with the additional 3-5 days to get back to therapeutic levels. Price will also be a major factor in deciding the role for the new anticoagulants. Dabigatran and rivaroxaban will cost over US $\$ 200$ per month while no price yet exists for apixaban. Despite the high cost, two 
Table 3. Advantages and disadvantages of anticoagulants.

\begin{tabular}{|c|c|c|}
\hline & Pros & Cons \\
\hline \multirow[t]{9}{*}{ Warfarin } & Long history of use & Narrow therapeutic window \\
\hline & Once-a-day dosing & Requires frequent monitoring \\
\hline & $\begin{array}{l}\text { Long half-life } \\
\text { Antidote for reversal }\end{array}$ & $\begin{array}{l}\text { Considerable amount of time is } \\
\text { required for its control }\end{array}$ \\
\hline & Affordable & Numerous drug and food interactions \\
\hline & & Genetic variation \\
\hline & & Slow onset of action \\
\hline & & Requires bridging during surgery \\
\hline & & Intracranial hemorrhage risk \\
\hline & & $\begin{array}{l}\text { Procoagulant effect through protein } \mathrm{C} \\
\text { and protein } \mathrm{S} \text { depletion }\end{array}$ \\
\hline \multirow[t]{8}{*}{ Dabigatran } & Fixed dosing & Twice-a-day dosing \\
\hline & Rapid onset of action & Gastrointestinal hemorrhage \\
\hline & Predictable PK/PD & Dyspepsia \\
\hline & $\begin{array}{l}\text { Lower } \mathrm{ICH} \text { risk compared with } \\
\text { warfarin }\end{array}$ & $\begin{array}{l}\text { No reliable monitoring in case of } \\
\text { bleeding or thrombosis }\end{array}$ \\
\hline & Dialyzable & Difficult to validate patient compliance \\
\hline & Minimal food and drug interactions & No known antidote for reversal \\
\hline & $\begin{array}{l}\text { No monitoring requirement } \\
\text { Can be stopped and restarted for }\end{array}$ & $\begin{array}{l}\text { The need for dose adjustment for } \\
\text { renal impairment }\end{array}$ \\
\hline & surgery without bridging & $\begin{array}{l}\text { Lack of long-term safety data } \\
\text { Cost }\end{array}$ \\
\hline \multirow[t]{7}{*}{ Rivaroxaban } & Fixed, once-a-day dosing & Lack of long-term safety data \\
\hline & $\begin{array}{l}\text { Predictable PK/PD } \\
\text { Effects reversed with prothrombin }\end{array}$ & $\begin{array}{l}\text { Dosing restrictions for renal } \\
\text { impairment }\end{array}$ \\
\hline & complex concentrate & No established therapeutic range \\
\hline & No monitoring requirement & Difficult to validate patient compliance \\
\hline & $\begin{array}{l}\text { warfarin } \\
\text { walsk comparea with }\end{array}$ & Cost (projected) \\
\hline & Minimal food and drug interactions & \\
\hline & $\begin{array}{l}\text { PT can be used to measure drug's } \\
\text { effect }\end{array}$ & \\
\hline \multirow[t]{8}{*}{ Apixaban } & $\begin{array}{l}\text { Superior to warfarin in preventing } \\
\text { strokes }\end{array}$ & \multirow{8}{*}{$\begin{array}{l}\text { Twice-a-day dosing } \\
\text { No known antidote for reversal } \\
\text { Lack of long-term safety data } \\
\text { Difficult to validate patient compliance } \\
\text { Cost (projected) }\end{array}$} \\
\hline & $\begin{array}{l}\text { Lower overall bleeding risk } \\
\text { compared to warfarin }\end{array}$ & \\
\hline & Fixed dosing & \\
\hline & Rapid onset of action & \\
\hline & Predictable PK/PD & \\
\hline & No monitoring requirement & \\
\hline & $\begin{array}{l}\text { Anti-FXa can be used to measure } \\
\text { drug's effect }\end{array}$ & \\
\hline & Minimal food and drug interactions & \\
\hline
\end{tabular}


cost-effectiveness analyses have shown that dabigatran may be a cost-effective alternative to warfarin [Freeman et al. 2010; Sorensen et al. 2011].

Both new and old anticoagulants have their advantages and disadvantages. Little is to be gained by switching a well-controlled patient from warfarin to new anticoagulants. However, the new anticoagulants would be of benefit in patients with labile INRs and in those who do not have an anticoagulation management program to sustain routine monitoring of INR or do not wish to take warfarin.

\section{Comparison of new anticoagulants}

At this time, there is no scientifically valid way to compare apixaban, rivaroxaban, and dabigatran as the trials evaluating their efficacy had different designs and study populations. Dabigatran and rivaroxaban have undergone thorough peer and FDA review. Apixaban data have not yet undergone the scrutiny that dabigatran and rivaroxaban data have. The ideal comparison of these drugs would be in a large, randomized, head-to-head comparative study. However, with the amount of revenue that could potentially be lost by the manufacturers if their drug was found inferior, the likelihood of such a trial is very unlikely. Dabigatran has shown difficulties with dyspepsia and gastrointestinal hemorrhage, while neither rivaroxaban nor apixaban seemed to have this particular adverseevent profile in clinical trials. The safety profiles of these drugs will become clearer with more widespread use. The data are strongest for apixaban. It was superior to warfarin and aspirin in the reduction of stroke and systemic embolism but was the only one of the three to also show a significant reduction in bleeding as well. There was a strong trend towards a reduction in mortality with dabigatran and rivaroxaban, but apixaban had a significant mortality reduction compared to warfarin. Of the new agents only rivaroxaban is a once-aday medication, which might be more convenient and able to increase adherence.

Personal preference and provider comfort will likely guide the decision to use one drug over another. However, selection may become clearer as these drugs are used more extensively.

\section{Funding}

This research received no specific grant from any funding agency in the public, commercial, or notfor-profit sectors.

\section{Conflict of interest statement}

The authors declare no conflict of interest in preparing this article.

\section{References}

Aguilar, M. and Hart, R. (2005) Antiplatelet therapy for preventing stroke in patients with non-valvular atrial fibrillation and no previous history of stroke or transient ischemic attacks. Cochrane Database Syst Rev CD001925.

Aithal, G.P., Day, C.P., Kesteven, P.J. and Daly, A.K. (1999) Association of polymorphisms in the cytochrome P450 Cyp2c9 with warfarin dose requirement and risk of bleeding complications. Lancet 353: 717-719.

Blech, S., Ebner, T., Ludwig-Schwellinger, E., Stangier, J. and Roth, W. (2008) The metabolism and disposition of the oral direct thrombin inhibitor, dabigatran, in humans. Drug Metab Dispos 36: 386-399.

Connolly, S., Pogue, J., Hart, R., Pfeffer, M., Hohnloser, S., Chrolavicius, S. et al. (2006) Clopidogrel plus aspirin versus oral anticoagulation for atrial fibrillation in the atrial fibrillation clopidogrel trial with irbesartan for prevention of vascular events (ACTIVE W): a randomised controlled trial. Lancet 367: 1903-1912.

Connolly, S.J., Eikelboom, J., Joyner, C., Diener, H.-C., Hart, R., Golitsyn, S. et al. (2011) Apixaban in patients with atrial fibrillation. $N \mathrm{Engl} \mathcal{F} \mathrm{Med}$, in press.

Connolly, S.J., Ezekowitz, M.D., Yusuf, S., Eikelboom, J., Oldgren, J., Parekh, A. et al. (2009) Dabigatran versus warfarin in patients with atrial fibrillation. $N$ Engl f Med 361: 1139-1151.

Connolly, S.J., Ezekowitz, M.D., Yusuf, S., Reilly, P.A. and Wallentin, L. (2010) Newly identified events in the RE-LY trial. N Engl F Med 363: 1875-1876.

Connolly, S.J., Laupacis, A., Gent, M., Roberts, R.S., Cairns, J.A. and Joyner, C. (1991) Canadian Atrial Fibrillation Anticoagulation (CAFA) study. $\mathcal{A} \mathrm{Am}$ Coll Cardiol 18: 349-355.

Connolly, S.J., Pogue, J., Eikelboom, J., Flaker, G., Commerford, P., Franzosi, M.G. et al. (2008) Benefit of oral anticoagulant over antiplatelet therapy in atrial fibrillation depends on the quality of international normalized ratio control achieved by centers and countries as measured by time in therapeutic range. Circulation 118: 2029-2037.

Couris, R., Tataronis, G., Mccloskey, W., Oertel, L., Dallal, G., Dwyer, J. et al. (2006) Dietary vitamin $\mathrm{K}$ variability affects international normalized ratio (INR) coagulation indices. Int $\mathcal{F}$ Vitam Nutr Res 76: $65-74$. 
De Assis, M.C., Rabelo, E.R., Avila, C.W., Polanczyk, C.A. and Rohde, L.E. (2009) Improved oral anticoagulation after a dietary vitamin K-guided strategy: a randomized controlled trial. Circulation 120: 1115-1122, $1113 \mathrm{p}$ following 1122 .

Diener, H.-C., Connolly, S.J., Ezekowitz, M.D., Wallentin, L., Reilly, P.A., Yang, S. et al. (2010) Dabigatran compared with warfarin in patients with atrial fibrillation and previous transient ischaemic attack or stroke: a subgroup analysis of the RE-LY trial. Lancet Neurol 9: 1157-1163.

Eerenberg, E.S., Kamphuisen, P.W., Sijpkens, M.K., Meijers, J.C., Buller, H.R., and Levi, M. (2011) Reversal of rivaroxaban and dabigatran by prothrombin complex concentrate: a randomized, placebo-controlled, crossover study in healthy subjects. Circulation 124: 1573-1579.

Eriksson, B.I., Quinlan, D.J. and Weitz, J.I. (2009) Comparative pharmacodynamics and pharmacokinetics of oral direct thrombin and factor $\mathrm{Xa}$ inhibitors in development. Clin Pharmacokinet 48: 1-22.

Eriksson, B.I., Smith, H., Yasothan, U. and Kirkpatrick, P. (2008) Dabigatran etexilate. Nat Rev Drug Discov 7: 557-558.

Ezekowitz, M. (2010) A Randomized Clinical Trial of Three Doses of a Long-Acting Oral Direct Factor Xa Inhibitor Betrixaban in Patients with Atrial Fibrillation (Explore-Xa). Available at: http://www. cardiosource.org/Science-And-Quality/ClinicalTrials/E/EXPLOREXa.aspx. (accessed 21 October 2011).

Ezekowitz, M.D., Bridgers, S.L., James, K.E., Carliner, N.H., Colling, C.L., Gornick, C.C. et al. (1992) Warfarin in the prevention of stroke associated with nonrheumatic atrial fibrillation. Veterans Affairs Stroke Prevention in Nonrheumatic Atrial Fibrillation Investigators. N Engl F Med 327: 1406-1412.

Ezekowitz, M.D., Reilly, P.A., Nehmiz, G., Simmers, T.A., Nagarakanti, R., Parcham-Azad, K. et al. (2007) Dabigatran with or without concomitant aspirin compared with warfarin alone in patients with nonvalvular atrial fibrillation (Petro Study). $A m \mathcal{F}$ Cardiol 100: 1419-1426.

Fang, M.C., Stafford, R.S., Ruskin, J.N. and Singer, D.E. (2004) National trends in antiarrhythmic and antithrombotic medication use in atrial fibrillation. Arch Intern Med 164: 55-60.

Franco, V., Polanczyk, C.A., Clausell, N. and Rohde, L.E. (2004) Role of dietary vitamin K intake in chronic oral anticoagulation: prospective evidence from observational and randomized protocols. Am $\mathcal{F}$ Med 116: 651-656.
Freeman, J.V., Zhu, R.P., Owens, D.K., Garber, A.M., Hutton, D.W., Go, A.S. et al. (2010) Costeffectiveness of dabigatran compared with warfarin for stroke prevention in atrial fibrillation. Ann Intern Med 154: 1-11.

Friberg, J., Buch, P., Scharling, H., Gadsbphioll, N. and Jensen, G.B. (2003) Rising rates of hospital admissions for atrial fibrillation. Epidemiology 14: 666-672.

Gage, B.F. (2009) Can we rely on RE-LY? N Engl f Med 361: 1200-1202.

Gage, B.F., Waterman, A.D., Shannon, W., Boechler, M., Rich, M.W. and Radford, M.J. (2001) Validation of clinical classification schemes for predicting stroke: results from the National Registry of Atrial Fibrillation. FAMA 285: 2864-2870.

Gladstone, D.J., Bui, E., Fang, J., Laupacis, A., Lindsay, M.P., Tu, J.V. et al. (2009) Potentially preventable strokes in high-risk patients with atrial fibrillation who are not adequately anticoagulated. Stroke 40: 235-240.

Go, A.S., Hylek, E.M., Chang, Y., Phillips, K.A., Henault, L.E., Capra, A.M. et al. (2003) Anticoagulation therapy for stroke prevention in atrial fibrillation: how well do randomized trials translate into clinical practice? $\mathcal{F} A M A$ 290: 2685-2692.

Granger, C.B., Alexander, J.H., Mcmurray, J.J., Lopes, R.D., Hylek, E.M., Hanna, M. et al. (2011) Apixaban versus warfarin in patients with atrial fibrillation. $N$ Engl f Med 365: 981-992.

Gurwitz, J.H., Field, T.S., Radford, M.J., Harrold, L.R., Becker, R., Reed, G. et al. (2007) The safety of warfarin therapy in the nursing home setting. $A m \mathcal{F}$ Med 120: 539-544.

Halabi, A., Kubitza, D., Zuehlsdorf, M., Becka, M., Mueck, W. and Maatouk, H. (2007) Effect of hepatic impairment on the pharmacokinetics, pharmacodynamics and tolerability of rivaroxaban an oral, direct factor Xa inhibitor. F Thromb Haemost 5: P-M-635.

Harper, P.L. and Pollock, D. (2008) Anticoagulant self-management using near patient testing and decision support software provided via an internet website improved anticoagulant control in patients on long-term warfarin. ASH Annual Meeting Abstracts 112: 1278-.

Hart, R.G., Pearce, L.A. and Aguilar, M.I. (2007) Meta-analysis: antithrombotic therapy to prevent stroke in patients who have nonvalvular atrial fibrillation. Ann Intern Med 146: 857-867.

Herman, D., Peternel, P., Stegnar, M., Breskvar, K. and Dolzan, V. (2006) The influence of sequence variations in factor VII, gamma-glutamyl carboxylase and vitamin 
K epoxide reductase complex genes on warfarin dose requirement. Thromb Haemost 95: 782-787.

Higashi, M.K., Veenstra, D.L., Kondo, L.M., Wittkowsky, A.K., Srinouanprachanh, S.L., Farin, F.M. et al. (2002) Association between Cyp2c9 genetic variants and anticoagulation-related outcomes during warfarin therapy. $\mathcal{F} A M A$ 287: 1690-1698.

Holbrook, A.M., Pereira, J.A., Labiris, R., Mcdonald, H., Douketis, J.D., Crowther, M. et al. (2005)

Systematic overview of warfarin and its drug and food interactions. Arch Intern Med 165: 1095-1106.

Jones, M., Mcewan, P., Morgan, C.L., Peters, J.R., Goodfellow, J. and Currie, C.J. (2005) Evaluation of the pattern of treatment, level of anticoagulation control, and outcome of treatment with warfarin in patients with non-valvar atrial fibrillation: a record linkage study in a large British population. Heart 91: 472-477.

Juurlink, D.N. (2007) Drug interactions with warfarin: what clinicians need to know. $C M A \mathcal{F} 177$ : 369-371.

Khan, T., Wynne, H., Wood, P., Torrance, A., Hankey, C., Avery, P. et al. (2004) Dietary vitamin K influences intra-individual variability in anticoagulant response to warfarin. Brf Haematol 124: 348-354.

Kubitza, D., Becka, M., Mueck, W., Halabi, A., Maatouk, H., Klause, N. et al. (2010) Effects of renal impairment on the pharmacokinetics, pharmacodynamics and safety of rivaroxaban, an oral, direct factor Xa inhibitor. Br f Clin Pharmacol 70: 703-712.

Kubitza, D., Becka, M., Roth, A. and Mueck, W. (2008) Dose-escalation study of the pharmacokinetics and pharmacodynamics of rivaroxaban in healthy elderly subjects. Curr Med Res Opin 24: 2757-2765.

Kubitza, D., Becka, M., Wensing, G., Voith, B. and Zuehlsdorf, M. (2005) Safety, pharmacodynamics, and pharmacokinetics of Bay 59-7939--an oral, direct factor Xa inhibitor--after multiple dosing in healthy male subjects. Eur f Clin Pharmacol 61: 873-880.

Kubitza, D., Becka, M., Zuehlsdorf, M. and Mueck, W. (2007) Body weight has limited influence on the safety, tolerability, pharmacokinetics, or pharmacodynamics of rivaroxaban (Bay 59-7939) in healthy subjects. F Clin Pharmacol 47: 218-226.

Kurnik, D., Loebstein, R., Rabinovitz, H., Austerweil, N., Halkin, H. and Almog, S. (2004) Over-thecounter vitamin $\mathrm{K} 1$-containing multivitamin supplements disrupt warfarin anticoagulation in vitamin $\mathrm{K} 1$-depleted patients. A prospective, controlled trial. Thromb Haemost 92: 1018-1024.

Leung, A.Y., Chow, H.C., Kwong, Y.L., Lie, A.K., Fung, A.T., Chow, W.H. et al. (2001) Genetic polymorphism in exon 4 of cytochrome P450 Cyp2c9 may be associated with warfarin sensitivity in Chinese patients. Blood 98: 2584-2587.

Liesenfeld, K.H., Schafer, H.G., Troconiz, I.F., Tillmann, C., Eriksson, B.I. and Stangier, J. (2006) Effects of the direct thrombin inhibitor dabigatran on ex vivo coagulation time in orthopaedic surgery patients: a population model analysis. $\mathrm{Br} \mathcal{F}$ Clin Pharmacol 62: 527-537.

Lin, H.J., Wolf, P.A., Kelly-Hayes, M., Beiser, A.S., Kase, C.S., Benjamin, E.J. et al. (1996) Stroke severity in atrial fibrillation. The Framingham Study. Stroke 27: 1760-1764.

Mackman, N. (2009) The role of tissue factor and factor VIIa in hemostasis. Anesth Analg 108: 1447-1452.

Mant, J., Hobbs, F.D., Fletcher, K., Roalfe, A., Fitzmaurice, D., Lip, G.Y. et al. (2007) Warfarin versus aspirin for stroke prevention in an elderly community population with atrial fibrillation (the Birmingham Atrial Fibrillation Treatment of the Aged Study, BAFTA): a randomised controlled trial. Lancet 370: 493-503.

Marini, C., De Santis, F., Sacco, S., Russo, T., Olivieri, L., Totaro, R. et al. (2005) Contribution of atrial fibrillation to incidence and outcome of ischemic stroke: results from a population-based study. Stroke 36: 1115-1119.

Matchar, D.B., Samsa, G.P., Cohen, S.J., Oddone, E.Z. and Jurgelski, A.E. (2002) Improving the quality of anticoagulation of patients with atrial fibrillation in managed care organizations: results of the managing anticoagulation services trial. Am F Med 113: 42-51.

Meckley, L.M., Wittkowsky, A.K., Rieder, M.J., Rettie, A.E., and Veenstra, D.L. (2008) An analysis of the relative effects of Vkorc1 and Cyp2c9 variants on anticoagulation related outcomes in warfarin-treated patients. Thromb Haemost 100: 229-239.

Miyasaka, Y., Barnes, M.E., Gersh, B.J., Cha, S.S., Bailey, K.R., Abhayaratna, W.P. et al. (2006) Secular trends in incidence of atrial fibrillation in Olmsted County, Minnesota, 1980 to 2000, and implications on the projections for future prevalence. Circulation 114: 119-125.

Nagarakanti, R., Ezekowitz, M.D., Oldgren, J., Yang, S., Chernick, M., Aikens, T.H. et al. (2011) Dabigatran versus warfarin in patients with atrial fibrillation: an analysis of patients undergoing cardioversion. Circulation 123: 131-136.

O'reilly, R.A. and Aggeler, P.M. (1968) Studies on coumarin anticoagulant drugs. initiation of warfarin therapy without a loading dose. Circulation 38: 169-177.

Ogata, K., Mendell-Harary, J., Tachibana, M., Masumoto, H., Oguma, T., Kojima, M. et al. (2010) 
Clinical safety, tolerability, pharmacokinetics, and pharmacodynamics of the novel factor Xa inhibitor edoxaban in healthy volunteers. F Clin Pharmacol 50: 743-753.

Oldgren, J., Alings, M., Darius, H., Eikelboom, J., Ezekowitz, M., Parekh, A. et al. (2010) Dabigatran etexilate versus warfarin in atrial fibrillation patients with low, moderate and high CHADS2 score - a RE-LY subgroup analysis. $\mathcal{F} \mathrm{Am}$ Coll Cardiol 55: A1.E2.

Patel, M.R., Mahaffey, K.W., Garg, J., Pan, G., Singer, D.E., Hacke, W. et al. (2011) Rivaroxaban versus warfarin in nonvalvular atrial fibrillation. N Engl F Med 365: 883-891.

Petersen, P., Boysen, G., Godtfredsen, J., Andersen, E.D. and Andersen, B. (1989) Placebo-controlled, randomised trial of warfarin and aspirin for prevention of thromboembolic complications in chronic atrial fibrillation. The Copenhagen Afasak Study. Lancet 1: 175-179.

Raghavan, N., Frost, C.E., Yu, Z., He, K., Zhang, H., Humphreys, W.G. et al. (2009) Apixaban metabolism and pharmacokinetics after oral administration to humans. Drug Metab Dispos 37: 74-81.

Roger, V.L., Go, A.S., Lloyd-Jones, D.M., Adams, R.J., Berry, J.D., Brown, T.M. et al. (2011) Heart disease and stroke statistics--2011 update: a report from the American Heart Association. Circulation 123: e18-e209.

Rohde, L.E., De Assis, M.C. and Rabelo, E.R. (2007) Dietary vitamin $\mathrm{K}$ intake and anticoagulation in elderly patients. Curr Opin Clin Nutr Metab Care 10: $1-5$.

Ruff, C.T., Giugliano, R.P., Antman, E.M., Crugnale, S.E., Bocanegra, T., Mercuri, M. et al. (2010) Evaluation of the novel factor Xa inhibitor edoxaban compared with warfarin in patients with atrial fibrillation: design and rationale for the effective anticoagulation with factor Xa next generation in atrial fibrillation-thrombolysis in myocardial infarction study 48 (ENGAGE AF-TIMI 48). Am Heart $\mathcal{F}$ 160: 635-641.

Ryan, F., Byrne, S. and O'shea, S. (2008) Randomized controlled trial of supervised patient self-testing of warfarin therapy using an internet based expert system. ASH Annual Meeting Abstracts 112: 879 .

Ryan, F., Byrne, S. and O'shea, S. (2009)

Randomized controlled trial of supervised patient self-testing of warfarin therapy using an internet-based expert system. F Thromb Haemost 7: 1284-1290.

Schurgers, L.J., Shearer, M.J., Hamulyak, K., Stocklin, E. and Vermeer, C. (2004) Effect of vitamin $\mathrm{K}$ intake on the stability of oral anticoagulant treatment: dose-response relationships in healthy subjects. Blood 104: 2682-2689.

Singer, D.E., Albers, G.W., Dalen, J.E., Fang, M.C., Go, A.S., Halperin, J.L. et al. (2008) Antithrombotic therapy in atrial fibrillation: American College of Chest Physicians evidence-based clinical practice guidelines (8th edition). Chest 133: 546S-592S.

Sorensen, S.V., Kansal, A.R., Connolly, S., Peng, S., Linnehan, J., Bradley-Kennedy, C. et al. (2011) Costeffectiveness of dabigatran etexilate for the prevention of stroke and systemic embolism in atrial fibrillation: A Canadian Payer Perspective. Thromb Haemost 105 , in press.

Stangier, J. (2008) Clinical pharmacokinetics and pharmacodynamics of the oral direct thrombin inhibitor dabigatran etexilate. Clin Pharmacokinet 47: 285-295.

Stangier, J., Rathgen, K., Stahle, H., Gansser, D. and Roth, W. (2007) The pharmacokinetics, pharmacodynamics and tolerability of dabigatran etexilate, a new oral direct thrombin inhibitor, in healthy male subjects. Br F Clin Pharmacol 64: 292-303.

Stangier, J., Rathgen, K., Stahle, H. and Mazur, D. (2010) Influence of renal impairment on the pharmacokinetics and pharmacodynamics of oral dabigatran etexilate: an open-label, parallel-group, single-centre study. Clin Pharmacokinet 49: 259-268.

Stangier, J., Stahle, H., Rathgen, K. and Fuhr, R. (2008) Pharmacokinetics and pharmacodynamics of the direct oral thrombin inhibitor dabigatran in healthy elderly subjects. Clin Pharmacokinet 47: 47-59.

Stroke Prevention in Atrial Fibrillation II Study Investigators (1994) Warfarin versus aspirin for prevention of thromboembolism in atrial fibrillation: Stroke Prevention in Atrial Fibrillation II Study. Lancet 343: 687-691.

Stroke Prevention in Atrial Fibrillation Study Investigators (1991) Stroke Prevention in Atrial Fibrillation Study. Final Results. Circulation 84: 527-539.

Taube, J., Halsall, D. and Baglin, T. (2000) Influence of cytochrome P-450 Cyp2c9 polymorphisms on warfarin sensitivity and risk of over-anticoagulation in patients on long-term treatment. Blood 96: 1816-1819.

The Boston Area Anticoagulation Trial for Atrial Fibrillation Investigators (1990) The effect of low-dose warfarin on the risk of stroke in patients with nonrheumatic atrial fibrillation. $N \mathrm{Engl} \mathcal{F ~ M e d}$ 323: 1505-1511.

The European Atrial Fibrillation Trial Study Group (1995) Optimal oral anticoagulant therapy in patients with nonrheumatic atrial fibrillation and recent cerebral ischemia. $N$ Engl f Med 333: 5-10. 
Van Ryn, J., Stangier, J., Haertter, S., Liesenfeld, K.H., Wienen, W., Feuring, M. et al. (2010) Dabigatran etexilate - a novel, reversible, oral direct thrombin inhibitor: interpretation of coagulation assays and reversal of anticoagulant activity. Thromb Haemost 103: 1116-1127.

Vecsler, M., Loebstein, R., Almog, S., Kurnik, D., Goldman, B., Halkin, H. et al. (2006) Combined genetic profiles of components and regulators of the vitamin K-dependent gamma-carboxylation system affect individual sensitivity to warfarin. Thromb Haemost 95: 205-211.

Veeger, N.J.G.M., Piersma-Wichers, M., Hillege, H.L., Crijns, H.J.G.M. and Van Der Meer, J. (2006) Early detection of patients with a poor response to vitamin $\mathrm{K}$ antagonists: the clinical impact of individual time within target range in patients with heart disease. f Thrombosis Haemostasis 4: 1625-1627.

Walenga, J.M. and Adiguzel, C. (2010) Drug and dietary interactions of the new and emerging oral anticoagulants. Int F Clin Pract 64: 956-967.

Wallentin, L., Yusuf, S., Ezekowitz, M.D., Alings, M., Flather, M., Franzosi, M.G. et al. (2010) Efficacy and safety of dabigatran compared with warfarin at different levels of international normalised ratio control for stroke prevention in atrial fibrillation: an analysis of the RE-LY trial. Lancet 376: 975-983.

Wang, L., Zhang, D., Raghavan, N., Yao, M., Ma, L., Frost, C.E. et al. (2010) In vitro assessment of metabolic drug-drug interaction potential of apixaban through cytochrome P450 phenotyping, inhibition,

Visit SAGE journals online http://taj.sagepub.com and induction studies. Drug Metab Dispos 38: 448-458.

Wann, L.S., Curtis, A.B., Ellenbogen, K.A., Estes, N.a.M., Ezekowitz, M.D., Jackman, W.M. et al.
(2011) $2011 \mathrm{ACCF} / \mathrm{AHA} / \mathrm{HRS}$ focused update on the management of patients with atrial fibrillation (update on dabigatran): a report of the American College of Cardiology Foundation/American Heart Association Task Force on Practice Guidelines. Circulation:

Weinz, C., Schwarz, T., Kubitza, D., Mueck, W. and Lang, D. (2009) Metabolism and excretion of rivaroxaban, an oral, direct factor Xa inhibitor, in rats, dogs, and humans. Drug Metab Dispos 37: 1056-1064.

Weitz, J.I., Connolly, S.J., Patel, I., Salazar, D., Rohatagi, S., Mendell, J. et al. (2010) Randomised, parallel-group, multicentre, multinational phase 2 study comparing edoxaban, an oral factor Xa inhibitor, with warfarin for stroke prevention in patients with atrial fibrillation. Thromb Haemost 104: 633-641.

White, H.D., Gruber, M., Feyzi, J., Kaatz, S., Tse, H.F., Husted, S. et al. (2007) Comparison of outcomes among patients randomized to warfarin therapy according to anticoagulant control: results from SPORTIF III and V. Arch Intern Med 167: 239-245.

Winkle, R.A., Mead, R.H., Engel, G., Kong, M.H. and Patrawala, R.A. (2011) The use of dabigatran immediately after atrial fibrillation ablation. f Cardiovasc Electrophysiol, in press.

Wolf, P.A., Abbott, R.D. and Kannel, W.B. (1991) Atrial fibrillation as an independent risk factor for stroke: The Framingham Study. Stroke 22: 983-988.

Zhang, P., Huang, W., Wang, L., Bao, L., Jia, Z.J., Bauer, S.M. et al. (2009) Discovery of betrixaban (Prt054021), N-(5-chloropyridin-2-Y1)-2-(4-

(N,N-dimethylcarbamimidoyl)benzamido)-5-meth oxybenzamide, a highly potent, selective, and orally efficacious factor Xa inhibitor. Bioorg Med Chem Lett 19: 2179-2185. 